\title{
The Contributions of Plastic Surgery to Care of the Spinal Cord Injured Patient
}

\author{
J. A. Buntine, FRACS, ${ }^{1}$ B. R. Johnstone $\mathbf{M B}$, BS $^{2}$ \\ ${ }^{1}$ Senior Plastic Surgeon, Austin Hospital, Heidelberg, Victoria, 3084, Australia. \\ ${ }^{2}$ Victorian Plastic Surgery Unit, Preston $\mathbb{E}$ Northcote Community Hospital, 205 \\ Bell Street, Preston, Victoria, 3072, Australia.
}

\begin{abstract}
Summary
Plastic surgeons have contributed to the understanding of pressure sore pathophysiology and prophylaxis. Increasingly sophisticated surgical techniques such as myocutaneous or innervated flaps add to the reliability and durability of repairs. The majority of quadriplegics may benefit from surgical restoration of active elbow extension, lateral pinch and grasp. Prolonged postoperative care in bed or immobilisation of the upper limb demands that patients should understand fully all that the reconstructive procedure involves. The nature and importance of subsequent rehabilitation must be appreciated by the patient so that he will be motivated to achieve the best possible result. Functional electrical stimulation may find an increasing role in the years to come.
\end{abstract}

Key words: Quadriplegia; Rehabilitation; Spinal cord injury; Tendon transfer; Pressure sores.

Surgical treatment of the complications of spinal cord injury has evolved over the past 25 years during which time several surgical specialties have become more firmly established. In many centres, plastic surgeons have undertaken the care of pressure sores and, along with orthopaedic surgeons and hand surgeons, have developed surgical procedures to upgrade upper limb function in quadriplegia. More recently surgeons have worked with engineers to develop functional electrical stimulation of paralysed muscles.

\section{The pathophysiology and prophylaxis of pressure sores}

Prolonged pressure, especially over bony prominences, causes ischaemic injury to tissues deprived of protective sensation. This is the primary cause of a pressure sore. Other factors which have been implicated include the adverse effect of 
shearing and frictional forces on the local circulation, direct trauma, obstruction of local lymphatics, limited regional autonomic responses, muscle spasm, regional muscle atrophy, faecal soiling, and maceration of the skin. General factors such as malnutrition may also contribute. Minor cutaneous infections cause induration and increase metabolic demands thus lowering resistance to pressure necrosis.

Experiments in pigs demonstrate muscle to be more sensitive to pressure damage than skin. With an applied pressure of $500 \mathrm{mmHg}$, muscle necrosis may occur after only 4 hours whereas skin necrosis occurs after application of 800 $\mathrm{mmHg}$ for eight hours or after $200 \mathrm{mmHg}$ for 16 hours (Daniel et al., 1981).

Over many months the weight bearing skin of a quadriplegic patient may become more tolerant of prolonged application of pressure. The mechanism is not understood but the skin itself appears to change and increasing mobility of the skin lessens the unfavourable effect of shearing strain upon the supplying blood vessels. One study (Fisher and Patterson 1983) showed that the average interval between episodes of pressure relief in a group of quadriplegic patients exceeded 1 hour and that the average ischial pressure for a $\mathrm{ROHO}$ cushion was $71.5 \mathrm{mmHg}$ and $105.4 \mathrm{mmHg}$ for polyurethane foam cushions.

Whilst in bed, patients should be turned from side to side every 2 hours although some patients tolerate up to 6 or 8 hours supine on a water bed or water filled overlay. The prone position on a row of pillows may be tolerated all night. Sheepskins with a heavy fleece help distribute pressure and reduce maceration by improving ventilation. Spasm may result in ulceration between the malleoli or knees or behind the heels. Such spasm may be reduced by medication e.g. Diazepam and, rarely, by ablative neurosurgical procedures. Suitably placed pillows and 'spasm sheets' are useful but spasm continues to cause difficulties. The Clinitron air fluidised bed (Dolezal et al, 1985) and the Mediscus * low air loss bed reduce pressure over bony prominences to 15 to 30 $\mathrm{mmHg}$. Special equipment of this type is appropriate for pre and post operative care of pressure sore prone patients, especially following repair of a pressure sore.

Independent paraplegic patients are commonly advised to prevent pressure sores by a regimen of pressure lifts lasting for 10 seconds every 10 minutes. Quadriplegic patients initially need pressure relief every 15 minutes but may, with carefully supervised training, tolerate 4 or 6 hours or even 8 hours of unrelieved pressure in the sitting position. Wheelchairs with electrically driven reclining backs increase pressure care independence. Frequent skin inspection, checking pressures with pressure monitoring pads, and modification of weight distribution are essential if skin tolerance is to be increased safely. Special pressure clinics have been developed in many spinal units. Pressure over the greater trochanters and ischia should be reduced to less than $60 \mathrm{mmHg}$ by adjusting inflation of a $\mathrm{ROHO}$ air balloon cushion or by carving the contour of medium density high resilience $8 \mathrm{~cm}$ thick polyurethane foam (Garber and Krouskop 1984). Gel and water filled devices may be used but blind faith must not be placed in any special type of cushion. Patients who throw more weight onto one side because of scoliosis, kyphosis, arthritis, or amputation of a leg, require specially contoured cushions, foam wedges, or ROHO cushions in which large subsections may be individually inflated. Such patients need careful follow up. 
At pressure clinics advice may be given on choice of clothing and footwear, splints, urine collecting devices, commodes and wheelchairs. Adjustment and maintenance of wheelchairs is reviewed. Techniques for transfer from bed to wheelchair etc., are supervised so as to avoid injury to insensitive areas.

Although the dangers are widely appreciated, long distance travel by road or air remains a frequent cause of severe pressure injury. While driving long distances, patients should stop every 30 minutes for a pressure relief lift lasting from 1 to 2 minutes. Complete pressure relief for 15 minutes is required every 2 to 3 hours. Cushions such as the low profile ROHO are a useful aid. Care must be taken to avoid burns from car heaters, hot flooring and interior fittings which have been heated by exposure to the sun.

The skin should be inspected thoroughly twice daily using a mirror for the weight bearing areas. Patients must be motivated and well disciplined so that pressure care becomes an integral part of daily life. Education concerning the pathophysiology and the consequences of pressure sores is essential. A fully employed and busy person must understand that he may be inconvenienced by a pressure care regimen but that treatment of an established pressure sore would interfere far more with his activities. Patients must appreciate that scars have an increased susceptibility to further pressure damage.

Patients must treat any areas of erythema, oedema, or induration with great respect. These early signs of pressure injury point to the need for complete protection of the part from further pressure injury. This may mean remaining prone in bed for 1 to 2 weeks.

Severe pressure sores result from gross self neglect, possibly with self destructive intent, associated with severe mental depression. Depressed patients are difficult to manage in the long term.

\section{Treatment of pressure sores}

Small areas of skin breakdown heal spontaneously with appropriate conservative treatment, the principle of which is 'putting anything on the pressure sore except the patient'. Bedbrook et al., (1985) report that $77.8 \%$ of pressure sores in Western Australia are treated at home. Advanced secondarily infected areas of fat necrosis associated with marked undermining, bone involvement, or surrounding fibrosis require surgical repair.

Primary care involves draining abscesses, ruthless debridement of necrotic tissue, and frequent packing with gauze soaked in povidone iodine or sodium hypochlorite solution. Enzymatic compounds may assist but are no substitute for thorough surgical debridement. Saline soaked packs are appropriate once the wound has become clean. Antibiotic therapy is indicated only for spreading local infection or septicaemia. Malnutrition, anaemia, or spasm may require treatment.

After 2 to 3 weeks most wounds are clean and somewhat reduced in size. Such wounds are ready for definitive surgery. Guttmann's pseudo-tumour technique involves packing of the sinus cavity with methylene blue soaked gauze, closure of the opening over the pack, and en bloc excision. The entire granulation lined sinus cavity, surrounding scar, calcified soft tissues, any adjacent bursa, and the surface of the underlying bone are excised. 
Total ischiectomy is no longer favoured as unilateral total ischiectomy transfers excessive weight onto the opposite side and bilateral ischiectomy is associated with long term urethral complications.

Direct closure of skin and deeper soft tissues has a place although the scar must cross a weight bearing zone. After direct closure in the ischial region, flexion of the hip may cause excessive tension on the scar. However, Bailey (1967) has pointed out that some part of the scar of a flap repair often passes over a weight bearing area and that scars from direct closure often do well which is consistent with our own experience.

Large random pattern cutaneous flaps (i.e. those not based upon the territory of distribution of an identifiable artery) are planned to place the scar away from pressure areas. Many designs allow direct closure of the secondary defect (the defect resulting from closure of the primary defect). If it is not possible to avoid split skin grafting of part of the secondary defect, it is important to place the skin graft so that it is subjected to neither pressure nor friction. Peri-operative prophylactic antibiotic cover is reasonable (often Flucloxacillin). One or more suction drains for up to 2 weeks helps to maintain apposition of tissue thus avoiding dead spaces. No weight should be borne by the scar until union is sound and until induration has subsided-usually 6 weeks. Weight bearing for increased periods is carefully supervised. If flexion of the hip pulls upon a recent scar, the hip is flexed progressively over a period of at least 10 days. Recurrent pressure sores may often be repaired by further advancement of a previous flap.

Local muscle flaps, e.g. flaps based upon the upper or lower half of the gluteus maximus muscle, may obliterate a cavity or increase local blood supply thus improving resistance to infection. However, it may not be sensible to rely unduly upon the padding effect of muscle for muscle is particularly sensitive to pressure necrosis and is not normally present over any weight bearing bony protuberance (Daniel \& Faibisoff 1982). (The lower edge of the gluteus maximus muscle normally slips upwards off the ischium when sitting).

Axial pattern flaps are based upon the territory of distribution of one or more identifiable cutaneous arteries. Neurovascular flaps include also a cutaneous nerve. Myocutaneous and fasciocutaneous flaps are axial pattern flaps. Some are also neurovascular flaps. Arteries supplying the skin may pass through a broad underlying muscle such as the gluteus maximus or may lie in intermuscular septa e.g. those between the upper ends of the hamstring muscles. The gluteus maximus muscle and its overlying skin, which is supplied by perforating vessels, may be used as a small or large ' $\mathrm{V}$ to $\mathrm{Y}$ ' advancement flap (Fisher et al., 1983) (Scheflan et al., 1981), as an island flap (Maruyama et al., 1980 ) or in toto as a large rotation flap (Parkash \& Banerjee 1986) with or without a fasciocutaneous extension to the posterior aspect of the thigh. Other flaps include the tensor fascia lata fasciocutaneous flap (McGregor \& Buchan 1980), the gracilis flap (McGregor 1982), the vastus lateralis myocutaneous flap (Hauben et al., 1983) and flaps that include any of the hamstring muscles (Scheflan 1981) (Hurteau et al., 1981).

Guttmann (1956) first suggested rotation of sensate flaps into areas of saddle anaesthesia. Dibbell (1974) repaired a sacral pressure sore with a musculocutaneous flap based upon the T10 inter-costal neurovascular bundle. In at 
least one case sensation has been shown to spread from this innervated flap to the surrounding skin (Shively et al., 1980). McGregor (1983) has provided a sensate repair of a lumbar pressure sore by transposing a medially based ('reversed') latissimus dorsi myocutaneous flap from above the level of anaesthesia. The lateral cutaneous nerve of the thigh may be included in a tensor fascia lata flap to provide a sensate repair if the level of sensory loss is below L2 or if the lateral cutaneous nerve within the flap is anastomosed to an intercostal nerve above the level of sensory loss (Coleman \& Jurkiewicz 1984). A further possibility is to innervate the lateral cutaneous nerve of the thigh within the flap by transposition of the medial cutaneous nerve of the forearm beneath the skin of the lateral chest wall (Mackinnon et al., 1985). It is stated that it is not usually possible to perform a direct connection between an inter-costal nerve or the medial cutaneous nerve of the forearm and the lateral cutaneous nerve of the thigh and so a sural nerve graft is usually required to bridge the gap.

\section{Surgical rehabilitation of the upper limb in quadriplegia}

Moberg (1975), Zancolli (1975), House et al., (1976) and Freehafer et al., (1974) have reported procedures designed to improve upper limb function in quadriplegia. Both Moberg and Zancolli have stated that at least $60 \%$ of quadriplegic patients may benefit from surgery and this is a percentage which is increasing. Older procedures for poliomyelitis and other types of paralysis involved multiple arthrodeses but, when applied to quadriplegia, these procedures led to clawed, inflexible and unattractive hands. Transfer of selected functioning muscles may activate tendons of key paralysed muscles or augment natural tenodesis i.e. the tendency for the fingers to flex as the wrist extends and vice versa. Moberg (1978) described softening and stretching or, alternatively, contracture of various ligaments resulting from an imbalance of muscular tone, the effects of gravity and poor proprioception. The quadriplegic patient loses control of most or all of the 37 muscles acting on the wrist and hand. The best that surgery can achieve is to replace these with one or two transferred muscles which may lack normal strength at the time of transfer.

Restoration of grasp and lateral pinch ('key pinch') is desirable for C6 and C7 quadriplegics but the final outcome is less satisfactory if thumb sensation is inadequate. Even when the brachioradialis muscle alone is of reasonable strength lateral pinch may be provided (Moberg 1975). If additional muscles such as extensor carpi radialis longus or pronator teres are available more complex procedures involving extensor and flexor phases may provide grasp (Zancolli 1975) (House 1985). An adduction-opponens plasty may be added (Freehafer et al., 1984) but true opposition and three point pinch can be attained only if the finger flexors have some function i.e. for low or C8 quadriplegics.

Provision of active elbow extension by transfer of the posterior third of the deltoid muscle into the triceps tendon is the most common single procedure. This may be achieved by free tendon grafts (Moberg 1975), fascia lata grafts from the leg (Hentz et al., 1983) or by reflection proximally of a central strip of triceps tendon (Castro-Sierra and Lopez-Pita 1983). Active elbow extension is useful for pressure lifts, transferring, and overhead activities. Function of distal tendon transfers is improved, particularly when the brachioradialis is used, as 
active elbow extension opposes unwanted flexion when the brachioradialis contracts. Further refinement of these procedures should reduce the period of postoperative splinting and thus make the procedures more acceptable to patients.

Satisfactory results require careful pre-operative assessment, planning, counselling, and meticulous surgical technique. A lengthy post-operative immobilisation and rehabilitation programme requires co-operation of a motivated patient.

\section{Conclusion}

Plastic surgeons may contribute to the efforts of a multi disciplinary team in preventing or treating pressure sores and thus assist rehabilitation of patients who have suffered the devastating effects of spinal cord injury. Conservative treatment and surgical repair of pressure sores requires a high standard of nursing care and rehabilitation and the long term result depends upon the patient's understanding of the causes of pressure injuries and his motivation to remain free from pressure sores.

Surgical treatment involves radical debridement and direct closure or flap repair. Axial pattern flaps, including myocutaneous flaps, are finding an increasing role. It is sometirnes possible to transpose an innervated flap into an anaesthetic area. It is also feasible to innervate a flap using a nerve from above the level of sensory loss.

Patients who are able to avoid pressure sores and other serious complications of quadriplegia are suitable candidates for reconstructive upper limb surgery which, in general, places even greater demands upon the patient and staff. However, it is now widely accepted that well informed highly motivated intelligent patients have much to gain from upper limb reconstruction.

\section{Acknowledgements}

We wish to thank Dr Douglas Brown, Director of the Spinal Injuries Unit of the Austin Hospital, for his enthusiastic support and Mrs Y. Duncan, Physiotherapist, for advice and assistance.

* Mediscus Products Limited, Westminster Rd., Wareham, Dorset BH20 4SP, UK.

\section{References}

BAILEY BN 1967 Bedsores, Edward Arnold (Publishers) Ltd., London.

Bedbrook G, Beer NIE, McLaren RK 1985 Preventive Measures in the Tertiary Care of Spinal Cord Injured People. Paraplegia 23:69-77.

Castro-Sierra A, Lopez-Pita A 1983 A New Surgical Technique to Correct Triceps Paralysis. Hand 15:42-46.

Coleman JJ, Jurkiewicz MJ 1984 Methods of Providing Sensation to Anaesthetic Areas. Annals of Plastic Surgery 12:177-186.

DANiEL RK, FAIBISOFF B 1982 Muscle Coverage of Pressure Points-The Role of Myocutaneous Flaps. Annals of Plastic Surgery 8:446-452.

DANIEL RK, PRIEST DL, WheATLEy DC 1981 Etiological Factors in Pressure Sores: An Experimental Model. Archives of Physical Medicine and Rehabilitation 62:492-498.

Dibbell DG 1974 Use of a Long Island Flap to bring Sensation to the Sacral Area in Young Paraplegics. Plastic and Reconstructive Surgery 54:220-223.

Dolezal R, Cohen M, Schultz RC 1985 The Use of Clinitron Therapy Unit in the Immediate Postoperative Care of Pressure Ulcers. Annals of Plastic Surgery 14:33-36.

Fisher J, ARNold PG, Waldorf J, Woods JE 1983 The Gluteus Maximus Musculocutaneous V-Y Advancement Flap for Large Sacral Defects. Annals of Plastic Surgery 11:517-522. 
Fisher SV, Patterson P 1983 Long Term Pressure Recordings under the Ischial Tuberosities of Tetraplegics. Paraplegia 21:99-106.

Freehafer AA, Kelly CM, Peckham PH 1984 Tendon Transfer for the Restoration of Upper Limb Function after a Cervical Spinal Cord Injury. Fournal of Hand Surgery 9A:887-893.

Freehafer AA, Von HaAm E, Allen V 1974 Tendon Transfers to Improve Grasp after Injuries of the Cervical Spinal Cord. Fournal of Bone and foint Surgery 56A:951-959.

GARBER SL, KROUSKOP TA 1984 Wheelchair Cushion Modification and its Effect on Pressure. Archives of Physical Medicine and Rehabilitation 65: 579-583.

Guttmann L 1956 The Problem of Treatment of Pressure Sores in Spinal Paraplegics. British Fournal of Plastic Surgery 8:196-213.

Hauben DJ, Smith AR, Sonneveld GJ, Van Der Meulen JC 1983 The Use of the Vastus Lateralis Myocutaneous Flap for the Repair of Trochanteric Pressure Sores. Annals of Plastic Surgery 10:359-363.

HeNTZ VR, BRown M, Keoshian LA 1983 Upper Limb Reconstruction in Quadriplegia: Functional Assessment and Proposed Treatment Modifications. Fournal of Hand Surgery 8:119-131.

HousE JH 1985 Reconstruction of the Thumb in Tetraplegia Following Spinal Cord Injury. Clinical Orthopaedics 195:117-128.

House JH, Gwathmey FW, LundsGaARd DK 1976 Restoration of Strong Grasp and Lateral Pinch in Tetraplegia due to Cervical Spinal Cord Injury. Fournal of Hand Surgery 1:152-159.

Hurteau JE, Bostwick J, Nahai F, Hester R, Jurkiewicz MJ 1981 V-Y Advancement of Hamstring Musculocutaneous Flaps for Coverage of Ischial Pressure Sores. Plastic Reconstructive Surgery 68:539-542.

Mackinnon SE, Dellon AL, Patterson GA, Gruss JS 1985 Medial Antebrachial CutaneousLateral Femoral Cutaneous Neurotization to Provide Sensation to Pressure-Bearing Areas in the Paraplegic Patient. Annals of Plastic Surgery 14:541-544.

Maruyama Y, Hakajima H, Wada M, Imai T, Fujino T 1980 A Gluteus Maximus Myocutaneous Island Flap for the Repair of a Sacral Decubitus Ulcer. British fournal of Plastic Surgery 33:150-155.

Moberg E 1975 Surgical Treatment for Absent Single-hand Grip and Elbow Extension in Quadriplegia. Fournal of Bone and foint Surgery 57A:196-206.

Moberg E 1978 The Upper Limb in Tetraplegia. A New Approach to Surgical Rehabilitation, George Thieme Publishers, Stuttgart.

MCGregor JC 1982 The Gracilis Musculocutaneous Flap as a Method of Closure of Ischial Pressure Sores: Preliminary Report. Paraplegia 20:217-226.

MCGREGOR JC 1983 The 'reverse' Latissimus Dorsi Myocutaneous Flap. fournal of the Royal College of Surgeons of Edinburgh 28:154-156.

MCGREgor JC, Buchan AC 1980 The Tensor Fasciae Latae Flap and its Use in the Closure of Trochanteric and Ischial Pressure Sores. Paraplegia 18:301-305.

PARKash S, BANERJEe S 1986 The Total Gluteus Maximus Rotation and other Gluteus Maximus Musculocutaneous Flaps in the Treatment of Pressure Ulcers. British fournal of Plastic Surgery 39:66-71.

Scheflan M 1982 Surgical Methods for Managing Ischial Pressure Wounds. Annals of Plastic Surgery 8:238-247.

SChEFlan M, Nahai F, Bostwick J 1981 Gluteus Maximus Island Musculocutaneous Flap for Closure of Sacral and Ischial Ulcers. Plastic Reconstructive Surgery 68:533-538.

Shively RE, Schafer ME, Kernahan DA 1980 The Spread of Sensibility into Previously Anaesthetic Skin following Intercostal Flap Transfer in a Paraplegic, Annals of Plastic Surgery 5:396-400.

ZaNCOLli E 1975 Surgery for the Quadriplegic Hand with Active, Strong Wrist Extension Preserved. A Study of 97 Cases. Clinical Orthopaedics 112:101-113. 